\title{
Mental capacity and psychiatric in-patients: implications for the new mental health law in England and Wales
}

Gareth S. Owen, George Szmukler, Genevra Richardson, Anthony S. David, Peter Hayward, James Rucker, Duncan Harding and Matthew Hotopf

\section{Background}

In England and Wales mental health services need to take account of the Mental Capacity Act 2005 and the Mental Health Act 1983. The overlap between these two causes dilemmas for clinicians.

\begin{abstract}
Aims
To describe the frequency and characteristics of patients who fall into two potentially anomalous groups: those who are not detained but lack mental capacity; and those who are detained but have mental capacity.
\end{abstract}

\section{Method}

Cross-sectional study of 200 patients admitted to psychiatric wards. We assessed mental capacity using a semi-structured interview, the MacArthur Competence Assessment Tool for Treatment (MacCAT-T).

\section{Results}

Of the in-patient sample, 24\% were informal but lacked capacity: these patients felt more coerced and had greater levels of treatment refusal than informal participants with capacity. People detained under the Mental Health Act with capacity comprised a small group (6\%) that was hard to characterise.

\section{Conclusions}

Our data suggest that psychiatrists in England and Wales need to take account of the Mental Capacity Act, and in particular best interests judgments and deprivation of liberty safeguards, more explicitly than is perhaps currently the case.

\section{Declaration of interest}

G.R. chaired the Expert Committee on the review of the Mental Health Act 1983. G.R., G.S. and A.S.D. all gave views to parliamentary committees over reform of the Mental Health Act 1983 where capacity was a central issue. These authors have differing views about mental capacity as a basis for mental health law. G.R. and G.S. are in favour of capacity-based mental health law. A.S.D. is against. M.H. has acted as an expert witness on cases where capacity has been under dispute.
Many jurisdictions in high-income countries maintain separate legal structures for the provision of mental healthcare based on risk on the one hand and incapacity on the other. England and Wales is now one of these jurisdictions and has the Mental Health Act 1983 and the Mental Capacity Act 2005. Both have been amended by the Mental Health Act 2007. Jurisdictions that maintain these separate frameworks need to manage the interface between them. In cases where detention in hospital is required this can cause legal difficulties, particularly for jurisdictions covered by the European Convention on Human Rights. This study addresses some of the dilemmas that can arise in the setting of admission to psychiatric hospital from the community.

The Mental Health Act establishes a framework for the provision of treatment, on an involuntary basis if necessary, to those suffering from mental disorder to the specified degree. The main criteria for its application are the presence of mental disorder and risk to the individual themselves or others (Appendix 1).

The Mental Capacity Act, on the other hand, provides a more general framework through which decisions, including those relating to medical treatment, may be taken on behalf of adults who lack decision-making capacity. The absence of capacity is the main criterion for its application. The Mental Health Act is primarily concerned with the reduction of risk both to the individual and to others, while the Mental Capacity Act is designed to enable the individual to make their own decisions as far as possible, to ensure that decisions reflect the individual's best interests and that the least restrictive intervention is used.
The Mental Health Act provides for the legal detention of people in hospital for treatment, but prior to the enactment of the Mental Capacity Act non-objecting individuals who lacked capacity were often accommodated in hospital informally, outside the Mental Health Act, using common law powers. ${ }^{1}$ This practice was held to breach the rights guaranteed by the European Convention on Human Rights in cases where the restrictions imposed on the individual amounted to a deprivation of liberty. ${ }^{2}$ In 2007 the Mental Capacity Act was amended to include the safeguards necessary to comply with the requirements of the European Convention on Human Rights in cases where a deprivation of liberty is required in the person's own best interests. Thus either statute could apply to adults with mental disorders who lack capacity and require treatment for those disorders, even when that treatment includes the deprivation of liberty. At the point of Mental Health Act assessment, clinicians will have the dilemma of which of the two frameworks to use. ${ }^{3}$ First, individuals lacking capacity can no longer be treated informally under the common law, the principles of the Mental Capacity Act must be applied if the Mental Health Act is not used. Second, if this treatment involves deprivation of liberty, then a choice must be made between detention under the Mental Health Act and the application of the deprivation of liberty safeguards under the amended Mental Capacity Act. ${ }^{4}$ The factors governing this choice include the presence of objections on the part of the individual. ${ }^{3,4}$

A different dilemma concerns people who are detained under the Mental Health Act with capacity. Although this practice is lawful, ${ }^{3}$ there have been concerns expressed about the ethics and 
the potentially stigmatising consequences of allowing mental health law based on risk to 'trump' mental health law based on capacity and individual autonomy. ${ }^{5-7}$

In this paper we aim to describe how existing psychiatric practice mapped on to this new legal landscape, specifically:

(a) what are the characteristics of informal patients meeting the incapacity criterion of the Mental Capacity Act? In particular, what is the degree of 'objecting' to treatment and how might this bear upon Mental Health Act detention;

(b) what are the characteristics of individuals detained under the Mental Health Act with capacity? Does recent self-harm or violence characterise this group;

(c) in individuals with capacity and without capacity, what predicts detention under the Mental Health Act?

\section{Method}

\section{Participants}

We performed a cross-sectional study based in three general adult acute psychiatric wards (one female and two male) at the Maudsley Hospital, London, UK. These wards serve part of Southwark, a deprived inner-London borough with an ethnically diverse population. The local research ethics committee approved the study.

Consecutive patients, admitted between February 2006 and June 2007, were identified by regular examination of the electronic medical records and consultations with the ward nursing staff. All admissions were included other than those admitted during planned research breaks. The sole exclusions were people from other catchment areas admitted to the wards and those transferred from other in-patient facilities. All individuals who spoke English were approached for a research interview. Those who assented were provided with full details of the study and the interview was stopped if there was any subsequent change in choice or resistance. Written consent was sought and participants were offered $£ 5$ for their time. Interviews were conducted as close to the admission as possible.

\section{Assessment of capacity}

Relevant information about the participant's presenting problems, diagnosis and treatment plan was obtained from the medical record and discussion with the clinical team. The clinical researcher (G.O.) determined whether the treating team's principal treatment recommendation at that time was stabilisation on medication or admission to a place of safety (hospitalisation). If it was medication, then the capacity assessment centred on the decision to take the recommended medication or not. If it was hospitalisation, then it was the capacity to decide on whether to come into hospital or not.

The presence or absence of capacity to decide on treatment was based on the two-stage test formulated in the Mental Capacity Act. This requires: evidence of 'an impairment of, or disturbance in, the functioning of the mind or brain' (Section 2(1)); and evidence that this impairment or disturbance means that the person is unable to make a specific decision (Section 3(1)). We interpreted the first stage of the test using clinical psychopathological concepts and ICD-10 diagnoses. ${ }^{8}$

The capacity judgement was facilitated by a clinical assessment (notes review and clinical interview) and the administration of the MacArthur Competence Assessment Tool for Treatment (MacCAT-T). ${ }^{9}$ The MacCAT-T is a semi-structured interview that provides relevant information disclosures to individuals about their illness (including its risks), the nature of treatment options and their risks and benefits. The assessor evaluates capacity in terms of four abilities relating to the disclosures: understanding, appreciation, reasoning and expressing a choice. These abilities map onto the abilities regarded as relevant by the Mental Capacity Act which are understanding, retaining, using, weighing and communicating. 'Using' is the term the Law Commission favoured in place of the term 'appreciation. ${ }^{10}$ We interpreted the terms to have equivalent meanings.

The judgement about capacity followed the approach outlined by Grisso \& Appelbaum. ${ }^{11}$ This incorporates the 'sliding scale' concept whereby decisions that carry a greater risk require greater evidence of the relevant decision-making abilities. This concept is similar to the English Law notion that the graver the consequences of the decision, the commensurately greater the level of competence that is required to make it.

The content of the MacCAT-T was modified for this study. When the principal treatment decision concerned medication, participants were given a disclosure about 'no medication' as the alternative to the 'recommended' medication rather than iterate through all medication options. This was done to simplify the interview and to reflect the main choice people who are acutely ill typically face. When the principal treatment decision concerned hospitalisation, participants were given a disclosure about the option of being an in-patient or not. Each disclosure involved giving the individual simple information about the nature of the option and its risks and benefits. The form of the MacCAT-T was left unaltered by these changes. Previous studies have demonstrated excellent interrater reliability $(\kappa>08)$ when the MacCAT-T is used in this way. ${ }^{12,13}$

\section{Other variables}

Details of status under the Mental Health Act were obtained from the clinical records. The Expanded Schedule for the Assessment of Insight (SAI-E) ${ }^{14}$ and the Brief Psychiatric Rating Scale (BPRS) ${ }^{15}$ were also administered. Both are clinically based, semi-structured interviews. The SAI-E comprises three main dimensions (awareness of illness, relabelling of symptoms as pathological and treatment adherence). We used the summary of adherence score (Item C of the SAI-E) as our measure of treatment refusal. This is a seven-point scale: $1=$ complete rejection of treatment; $2=$ partial rejection; $3=$ reluctant acceptance; $4=$ occasional reluctance; $5=$ passive acceptance; $6=$ moderate participation; $7=$ active participation. We used the relabelling score because it has conceptual similarity with 'use' (in the Mental Capacity Act). This scale measures the extent to which symptoms that the clinical interview has highlighted as indicators of illness can be regarded as such by the patient. We separated relabelling from treatment refusal because they are conceptually distinguishable. We adjusted the total BPRS score to account for domains of psychopathology that were not assessable (e.g. hallucinations in an individual who was mute) by summing subscores and dividing the total by the number of BPRS domains that were assessable. This was done to obtain a measure of total symptoms that was not misleadingly low in participants who did not respond to questions about symptoms. Level of symptoms is sometimes used with 'insight' to interpret 'nature and degree' (in the Mental Health Act). Broad ICD-10 categories were used for the main mental disorder.

We recorded acts of self-harm and violence in the period 2 weeks prior to admission until the point of assessment using information from the medical records, nursing staff and selfreport. To structure this we used the Modified Overt Aggression Scale. ${ }^{16}$ 
We used the MacArthur Admissions Experience Survey ${ }^{17}$ to collect information relating to subjective coercion. This relates to recent admission and includes measures of participants' perceived coercion, recall of negative pressures and sense of 'voice' in the admission procedure.

\section{Statistical analysis}

Analyses were performed using Stata 9.2 for Windows. Conventional bivariate methods were used to compare participant groups.

\section{Results}

Details on the 350 consecutive admissions with prevalence estimates of mental incapacity are reported elsewhere. ${ }^{18}$ Two hundred people were interviewed by the researcher. Individuals interviewed were similar to individuals not interviewed on diagnosis, number of previous admissions, length of contact with services and global assessment of functioning. People not interviewed had significantly higher levels of treatment refusal than those interviewed with a trend to being more frequently detained (details available from the author on request).

Decision-making capacity status and status under the Mental Health Act divides participants into four broad groups: informal/ capacity, informal/incapacity, detained/capacity, detained/ incapacity. (Informal participants are those in respect of whom no Mental Health Act powers have been taken.) Table 1 shows participants according to these groups. In each group the types of mental disorder (ICD-10) and, where applicable, the Mental Health Act section is summarised.

Tables 2 and 3 address informal and detained participants respectively. Explanations of the scales used are given as footnotes. Table 2 shows the differences between informal participants with and without capacity. In informal participants, levels of treatment refusal and negative experience of admission were significantly higher in the incapacity group than in the capacity group. In the incapacity group the median value of treatment refusal was 5 (passive acceptance of treatment) with the interquartile range between 4 and 6 (occasional reluctance to moderate participation). When treatment refusal was converted to a binary variable using a cut-off score of less than 5 (treatment adherence less than passive acceptance) to indicate 'objection' to treatment then 18 participants without capacity $(38 \%)$ objected and incapacity associated with 'objection' to treatment $\left(\chi^{2}=20.1\right.$, $P<0.001$ ). If the cut-off score was set at less than 3 (any rejection of treatment) then only three participants without capacity (6\%) 'objected' although incapacity was still associated with 'objection' $\left(\chi^{2}=4.78, P<0.03\right)$. Symptom levels were significantly higher and ability to relabel symptoms as pathological were lower in the individuals without capacity. Levels of recent self-harm and violence showed no significant difference.

Table 3 shows the differences between detained participants with and without capacity. In detained individuals, levels of treatment refusal and negative experience of admission did not differ by capacity status. Levels of symptoms were higher and ability to relabel those symptoms as pathological was significantly lower in the participants without capacity. Recent violence showed no significant difference but recent self-harm was significantly higher in those with capacity.

Tables 4 and 5 address participants with and without capacity respectively. Table 4 shows the variables which associate with detention in participants with capacity. The only variable which was associated with detention in participants with capacity was treatment refusal. Recent self-harm or violence, levels of

\begin{tabular}{lcc} 
Table 1 Mental disorder and legal status & \\
& Capacity & Incapacity \\
Informal, $n$ & 73 & 47 \\
Mental disorder, $n$ (\%) & & \\
Psychotic episode & $10(13.7)$ & $11(23.4)$ \\
Schizophrenia & $6(8.2)$ & $11(23.4)$ \\
Schizoaffective disorder & $1(1.4)$ & $5(10.6)$ \\
Bipolar affective disorder, manic phase & $1(1.4)$ & $5(10.6)$ \\
Bipolar affective disorder, depressed & & \\
phase & $5(6.9)$ & $1(2.1)$ \\
Depression & $29(39.7)$ & $11(23.4)$ \\
Personality disorder & $14(19.2)$ & 0 \\
Post-traumatic stress disorder & $1(1.4)$ & 0 \\
Organic & 0 & $1(2.1)$ \\
Other & $6(8.2)$ & $2(4.3)$ \\
\hline Detained, $n$ & 12 & 68 \\
Mental disorder, $n$ (\%) & & \\
Psychotic episode & $5(41.7)$ & $18(26.5)$ \\
Schizophrenia & $2(16.7)$ & $20(29.4)$ \\
Schizophrenia disorder & 0 & $4(5.9)$ \\
Bipolar affective disorder, manic phase & 0 & $17(25.0)$ \\
Bipolar affective disorder, depressed & & \\
phase & 0 & 0 \\
Depression & $2(16.7)$ & $4(5.9)$ \\
Personality disorder & 0 & $1(1.5)$ \\
Post-traumatic stress disorder & $2(16.7)$ & $1(1.5)$ \\
Organic & 0 & $3(4.4)$ \\
Other & $1(8.3)$ & \\
Mental Health Act applies, section: $n$ (\%) & & \\
S.4 & 0 & $1(1.4)$ \\
5.2 & $2(16.7)$ & $19(27.9)$ \\
S.2 & $9(75.0)$ & $27(39.7)$ \\
S.3 & $1(8.3)$ & $20(29.4)$ \\
Court order & 0 & $1(1.5)$ \\
\hline
\end{tabular}

symptoms or inability to relabel symptoms as pathological were not associated with detention. To obtain a clearer understanding of this important group of individuals, we examined in detail the case records concerning the circumstances of admission for the 12 people with capacity who were detained. They fell into three groups:

(a) five participants (three with a psychosis) probably lacked capacity at the time of admission, but then made a rapid improvement;

(b) five participants (two with a psychosis) presented with recent behaviour indicating a risk of future self-harm (four individuals) or of violence (one person) and it was unclear what the individual' intentions were;

(c) two people with a psychosis with extensive previous contact with services engineered an involuntary admission to ensure they were admitted, probably to gain respite from problems in the community.

Table 5 shows the variables that were associated with detention in individuals without capacity. Treatment refusal, recent violence and inability to relabel symptoms as pathological were all associated with detention. Total symptoms were not associated with detention. Recent self-harm was associated with informal care.

\section{Discussion}

\section{Main findings}

People admitted to psychiatric hospital from the community span all four groups created by capacity law and the Mental Health Act: 


\begin{tabular}{|c|c|c|c|c|}
\hline Variable & $\begin{array}{l}\text { Informal capacity } \\
\qquad(n=73)\end{array}$ & $\begin{array}{l}\text { Informal incapacity } \\
\qquad(n=47)\end{array}$ & Test statistic & $P$ \\
\hline $\begin{array}{l}\text { Treatment refusal } \\
\quad \text { Mean (s.d.) } \\
\text { Range } \\
\text { Median (IQR) }\end{array}$ & $\begin{array}{l}6.2(0.8) \\
3-7 \\
6(6-7) \\
\end{array}$ & $\begin{array}{c}4.7(1.3) \\
2-7 \\
5(4-6) \\
\end{array}$ & $t=-7.77\left(\mathrm{~d} . \mathrm{f}_{\mathrm{f}}=118\right)$ & $<0.001$ \\
\hline $\begin{array}{l}\text { Experience of admission, median (IQR) } \\
\text { Perceived coercion } \\
\text { Negative pressures }^{\mathrm{c}} \\
\text { Voice }^{\mathrm{d}}\end{array}$ & $\begin{array}{l}1(0-3) \\
0(0-1) \\
3(2-3)\end{array}$ & $\begin{array}{l}3(1-4) \\
1(0-3) \\
2(0-2)\end{array}$ & $\begin{array}{c}\text { Mann-Whitney } z=2.7 \\
\text { Mann-Whitney } z=4.4 \\
\text { Mann-Whitney } z=-3.4\end{array}$ & $\begin{array}{r}0.007 \\
<0.001 \\
<0.001\end{array}$ \\
\hline $\begin{array}{l}\text { Recent self-harm, } n \text { (\%) } \\
\text { No self-harm } \\
\text { Minor self-injury } \\
\text { Major self-injury or suicide attempt }\end{array}$ & $\begin{array}{c}40(54.8) \\
6(8.2) \\
27(37.0)\end{array}$ & $\begin{array}{c}34(72.3) \\
1(2.1) \\
12(25.5)\end{array}$ & $\chi^{2}=4.4($ d.f. $=2)$ & 0.11 \\
\hline $\begin{array}{l}\text { Recent violence, } n(\%) \\
\text { No physical aggression } \\
\text { Physical aggression without causing injury } \\
\text { Physical aggression causing injury }\end{array}$ & $\begin{array}{l}64(87.7) \\
4(5.5) \\
5(6.9)\end{array}$ & $\begin{array}{l}40(85.1) \\
5(10.6) \\
2(4.3)\end{array}$ & $\chi^{2}=1.4($ d.f. $=2)$ & 0.51 \\
\hline Symptoms, ${ }^{e}$ mean (s.d) & $1.8(0.3)$ & $2.3(0.6)$ & $t=6.7($ d.f. $=118)$ & $<0.001$ \\
\hline Relabelling of symptoms as pathological, ${ }^{f}$ mean (s.d) & $9.3(2.5)$ & $4.2(3.2)$ & $t=-9.7($ d.f. $=115)$ & $<0.001$ \\
\hline \multicolumn{5}{|c|}{$\begin{array}{l}\text { IQR, interquartile range. } \\
\text { a. Treatment refusal: } 1 \text { (complete rejection), } 2 \text { (partial rejection), } 3 \text { (reluctant acceptance), } 4 \text { (occasional reluctance), } 5 \text { (passive acceptance), } 6 \text { (moderate participation), } 7 \text { (active } \\
\text { participation). } \\
\text { b. Perceived coercion: } 1 \text { (no perceived coercion), } 5 \text { (maximum perceived coercion). } \\
\text { c. Negative pressure: } 1 \text { (no negative pressures), } 5 \text { (maximum negative pressures). } \\
\text { d. Voice: } 1 \text { (no voice) to } 3 \text { (full voice). } \\
\text { e. Symptoms: } 1 \text { (none). } \\
\text { f. Relabelling: } 0 \text { (no ability to relabel symptoms as pathological) to } 12 \text { (full ability to relabel symptoms). }\end{array}$} \\
\hline
\end{tabular}

\begin{tabular}{|c|c|c|c|c|}
\hline Variable & $\begin{array}{l}\text { Detained capacity } \\
\qquad(n=12)\end{array}$ & $\begin{array}{l}\text { Detained incapacity } \\
\qquad(n=68)\end{array}$ & Test statistic & $P$ \\
\hline Treatment refusal, ${ }^{a}$ mean (s.d.) & $3.5(1.9)$ & $2.6(1.4)$ & $t=-2.0$ (d.f. $=78)$ & 0.05 \\
\hline \multicolumn{5}{|l|}{ Experience of admission, median (IQR) } \\
\hline Perceived coercion ${ }^{b}$ & $4.5(2-5)$ & $3.5(2-5)$ & Mann-Whitney $z=-0.6$ & 0.54 \\
\hline Negative pressures $^{c}$ & $2(1-5)$ & $4(1-5)$ & Mann-Whitney $z=1.3$ & 0.19 \\
\hline Voice $^{\mathrm{d}}$ & $1(1-2)$ & $1.5(0-2)$ & Mann-Whitney $z=0.37$ & 0.71 \\
\hline \multicolumn{5}{|l|}{ Recent self-harm, $n(\%)$} \\
\hline No self-harm & $8(66.7)$ & $63(92.7)$ & Fisher's exact & 0.008 \\
\hline Minor self-injury & 0 & $3(4.4)$ & & \\
\hline Major self-injury or suicide attempt & $4(33.3)$ & $2(2.9)$ & & \\
\hline \multicolumn{5}{|l|}{ Recent violence, $n(\%)$} \\
\hline No physical aggression & $10(83.3)$ & $41(60.3)$ & Fisher's exact & 0.35 \\
\hline Physical aggression without causing injury & $2(16.7)$ & $19(27.9)$ & & \\
\hline Physical aggression causing injury & 0 & $8(11.8)$ & & \\
\hline Symptoms, ${ }^{\text {e }}$ mean (s.d) & $1.7(0.4)$ & $2.3(0.7)$ & $t=3.0($ d.f. $=78)$ & 0.004 \\
\hline Relabelling of symptoms as pathological, ${ }^{f}$ mean (s.d) & $7.9(3.1)$ & $2.5(2.4)$ & $t=-7.0$ (d.f. $=72)$ & $<0.001$ \\
\hline \multicolumn{5}{|c|}{$\begin{array}{l}\text { IQR, interquartile range. } \\
\text { a. Treatment refusal: } 1 \text { (complete rejection), } 2 \text { (partial rejection), } 3 \text { (reluctant acceptance), } 4 \text { (occasional reluctance), } 5 \text { (passive acceptance), } 6 \text { (moderate participation), } 7 \text { (active } \\
\text { participation). } \\
\text { b. Perceived coercion: } 1 \text { (no perceived coercion), } 5 \text { (maximum perceived coercion). } \\
\text { c. Negative pressure: } 1 \text { (no negative pressures), } 5 \text { (maximum negative pressures). } \\
\text { d. Voice: } 1 \text { (no voice) to } 3 \text { (full voice). } \\
\text { e. Symptoms: } 1 \text { (none). } \\
\text { f. Relabelling: } 0 \text { (no ability to relabel symptoms as pathological) to } 12 \text { (full ability to relabel symptoms). }\end{array}$} \\
\hline
\end{tabular}

capacity/informal, incapacity/informal, capacity/detained and incapacity/detained. The largest groups are capacity/informal (37\%) and incapacity/detained (34\%). Approximately a third fell into the legally and ethically more problematic categories of incapacity/informal and capacity/detained. Of these, the incapacity/ informal group was large, comprising $24 \%$ of the sample. Most people in this group have a psychotic illness or depression as the main mental disorder, a pattern similar to that of the detained/incapacity group. With regard to the provision of treatment to this incapacity/informal group the principles of the Mental Capacity Act will now apply, thus any treatment given will have to be in the person's best interests and be the least restrictive alternative. However, if this treatment involves deprivation of liberty under article 5, European Convention on Human Rights, then a choice will have to be made between detention under the Mental Health Act and the application of the deprivation of liberty 


\begin{tabular}{|c|c|c|c|c|}
\hline Variable & $\begin{array}{l}\text { Capacity informal } \\
\qquad(n=73)\end{array}$ & $\begin{array}{l}\text { Capacity detained } \\
\qquad(n=12)\end{array}$ & Test statistic & $P$ \\
\hline Treatment refusal, ${ }^{a}$ mean (s.d.) & $6.2(0.8)$ & $3.5(1.9)$ & $t=8.3(\mathrm{~d} . \mathrm{f} .=83)$ & $<0.001$ \\
\hline \multicolumn{5}{|l|}{ Recent self-harm, $n(\%)$} \\
\hline No self-harm & $40(54.8)$ & $8(66.7)$ & \multirow[t]{3}{*}{ Fisher's exact } & \multirow[t]{3}{*}{0.70} \\
\hline Minor self-injury & $6(8.2)$ & 0 & & \\
\hline Major self-injury or suicide attempt & $27(37.0)$ & $4(33.3)$ & & \\
\hline \multicolumn{5}{|l|}{ Recent violence, $n$ (\%) } \\
\hline No physical aggression & $64(87.7)$ & $10(83.3)$ & \multirow[t]{3}{*}{ Fisher's exact } & \multirow[t]{3}{*}{0.32} \\
\hline Physical aggression without causing injury & $4(5.5)$ & $2(16.7)$ & & \\
\hline Physical aggression causing injury & $5(6.9)$ & 0 & & \\
\hline Total symptoms, ${ }^{\mathrm{b}}$ mean (s.d) & $1.8(0.3)$ & $1.7(0.3)$ & $t=0.82$ (d.f. $=83)$ & 0.41 \\
\hline Relabelling of symptoms as pathological, ${ }^{\mathrm{c}}$ mean (s.d) & $9.3(2.5)$ & $7.9(3.1)$ & $t=1.7$ (d.f. $=83)$ & 0.09 \\
\hline
\end{tabular}

\begin{tabular}{|c|c|c|c|c|}
\hline Variable & $\begin{array}{l}\text { Incapacity informal } \\
\qquad(n=47)\end{array}$ & $\begin{array}{l}\text { Incapacity detained } \\
\qquad(n=68)\end{array}$ & Test statistic & $P$ \\
\hline Treatment refusal, ${ }^{a}$ mean (s.d.) & $4.7(1.3)$ & $2.6(1.4)$ & $t=8.2(\mathrm{~d} . \mathrm{f} .=113)$ & $<0.001$ \\
\hline \multicolumn{5}{|l|}{ Recent self-harm, $n(\%)$} \\
\hline No self-harm & $34(72.3)$ & $63(92.7)$ & \multirow{3}{*}{ Fisher's exact } & \multirow{3}{*}{0.001} \\
\hline Minor self-injury & $1(2.1)$ & $3(4.4)$ & & \\
\hline Major self-injury or suicide attempt & $12(25.5)$ & $2(2.9)$ & & \\
\hline \multicolumn{5}{|l|}{ Recent violence, $n(\%)$} \\
\hline No physical aggression & $40(85.1)$ & $41(60.3)$ & \multirow[t]{3}{*}{ Fisher's exact } & \multirow[t]{3}{*}{0.02} \\
\hline Physical aggression without causing injury & $5(10.6)$ & $19(27.9)$ & & \\
\hline Physical aggression causing injury & $2(4.3)$ & $8(11.8)$ & & \\
\hline Total symptoms, ${ }^{\mathrm{b}}$ mean (s.d) & $2.3(0.6)$ & $2.3(0.7)$ & $t=0.09$ (d.f. $=113)$ & 0.93 \\
\hline Relabelling of symptoms as pathological, ${ }^{\mathrm{C}}$ mean (s.d) & $4.2(3.2)$ & $2.5(2.4)$ & $t=3.2($ d.f. $=104)$ & 0.002 \\
\hline \multicolumn{5}{|c|}{$\begin{array}{l}\text { a. Treatment refusal: } 1 \text { (complete rejection), } 2 \text { (partial rejection), } 3 \text { (reluctant acceptance), } 4 \text { (occasional reluctance), } 5 \text { (passive acceptance), } 6 \text { (moderate participation), } 7 \text { (active } \\
\text { participation). } \\
\text { b. Symptoms } 1 \text { (none). } \\
\text { c. Relabelling: } 0 \text { (no ability to relabel symptoms as pathological) to } 12 \text { (full ability to relabel symptoms). }\end{array}$} \\
\hline
\end{tabular}

safeguards under the amended Mental Capacity Act. Thus, in relation to this significant group of individuals, clinicians will have to become familiar with the identification of deprivations of liberty and with the factors governing the choice of legislative framework, including the person's objections to treatment. In relation to the presence of 'objection', the data indicate that informal patients without capacity have higher levels of treatment refusal, perceived coercion and negative treatment pressures on admission and a reduced sense of 'voice' compared with informal patients with capacity. The majority of people in this group have levels of treatment refusal between occasional reluctance and moderate participation. If any level of treatment adherence less than 'passive acceptance' is taken as a marker for 'objecting' to treatment then incapacity associates with 'objection' in informal patients. Such a level of objection might amount to grounds for preferring Mental Health Act detention to deprivation of liberty under the Mental Capacity Act. This could lead to an increase in the use of the Mental Health Act in relation to previously informal patients who are deprived of their liberty. Much will depend on how 'deprivation of liberty' and 'objecting' to treatment are interpreted by clinicians and ultimately by the courts - both will become significant legal concepts yet both pose challenges of interpretation.
The capacity/detained group was small (6\%). About a third probably lacked capacity at the time of admission but had recovered it by the time of interview. Most are on assessment sections of the Mental Health Act. Surprisingly, participants in this group did not feel more coerced than those without capacity who are detained. They were less symptomatic and better able to relabel their symptoms as pathological, an important aspect of insight. ${ }^{19}$ They self-harmed more but were neither more nor less violent. In some cases, previous risky behaviour in someone whose further intentions were not clear was a key factor. There have been human rights concerns about detaining individuals with capacity. ${ }^{20,21}$ It might be expected that this group would be characterised less by psychotic illness, and more by people with personality disorders posing considerable risk of harming themselves or others. In this study over half of these individuals had psychotic illnesses as the main diagnosis, and none had personality disorder as the main diagnosis. However, the sample size for these analyses was small, making it difficult to draw firm conclusions. Further, it is possible that the existence of this group simply reflects a few inevitable 'false negative' errors in the capacity classification (or 'false positive' errors in the application of the Mental Health Act).

Which factors are associated with detention on admission to psychiatric hospital? We found that irrespective of capacity, 
treatment refusal rather than recent violence or self-harm was most strongly associated with detention. This suggests that it is the perceived need for treatment by the clinical team in the face of resistance from the individual that drives detention under the Mental Health Act rather than recent self-harm or violence. The only positive association of detention in participants with capacity is treatment refusal. Relabelling of symptoms did not associate with detention in this group. Although recent self-harm or violence were not associated with detention for the group as a whole, it was important for a subgroup of people where it was difficult to assess the individual's intentions in respect of a repetition of self-harm or violence. The associations of detention in people without capacity go beyond treatment refusal and include recent violence and inability to relabel symptoms. This suggests that in clinical practice the significance of recent violence depends upon capacity status and the related concept of ability to relabel symptoms as pathological. When capacity is absent, recent violence seems more likely to trigger detention than when capacity is present.

\section{Methodological shortcomings}

This is the largest study of mental capacity in a psychiatric setting yet conducted, although as the study was carried out in an urban setting in one jurisdiction it may not generalise to other psychiatric in-patient settings. Previous studies were limited by the use of convenience samples or not including an overall judgement of capacity for a clinically significant decision. ${ }^{14}$ We used a strictly consecutive sample and expanded treatment decisions to include hospitalisation if this was the significant treatment decision. Fifty-seven per cent of all admissions participated in the assessment by the researcher. This raises the issue of non-participation potentially creating a non-representative sample. Our comparisons of non-participants and participants on basic clinical and legal variables suggested that the participants were reasonably representative of the individuals admitted.

Our assessments of capacity were not carried out at the precise time of the clinical decision to admit the person to hospital. The majority were carried out within 3 days. This time lag could be a problem for missing rapidly fluctuating capacity status but we believe that this is only likely to be a major factor in the setting of emotional crises (e.g. surrounding self-harm), or drug or alcohol intoxication. The majority of individuals who were admitted had psychotic or serious affective illnesses that are unlikely to involve significant capacity fluctuation over the course of a few days.

\section{Clinical and legal implications}

Clinicians now face a more complex landscape of mental health law. They will have to navigate two legal frameworks, the Mental Health Act 1983 and the Mental Capacity Act 2005, and keep in mind the unfolding meaning of 'deprivation of liberty' and 'objecting' to treatment. This study maps existing psychiatric practice onto this more complex legal landscape to show us some of the implications. However, it was not able to resolve the question of how prevalent 'deprivation of liberty' is in the in-patient setting.

Although systematic study of the practice of mental health law inevitably requires attention to specific jurisdictions (in this case England and Wales) we think this study helps to illuminate relationships between mental health law and guardianship/ incapacity law existing across many jurisdictions in the developed world. How these dual legal frameworks will affect psychiatric practice itself over time is yet to be seen.
Gareth S. Owen, MRCPsych, Department of Psychological Medicine and Psychiatry, George Szmukler, FRCPsych, Health Service and Research Department, Institute of Psychiatry, King's College London; Genevra Richardson, LLM, School of Law, King's College London, Anthony S. David, FRCPsych, Department of Psychological Medicine and Psychiatry, Institute of Psychiatry, King's College London; Peter Hayward, PhD, Department of Psychology; James Rucker, MRCPsych, Social, Genetic, Developmental Psychiatry Centre, Institute of Psychiatry, King's College London; Duncan Harding, MRCPsych, Maudsley Hospital, London; Matthew Hotopf, MRCPsych, PhD, Department of Psychological Medicine and Psychiatry, Institute of Psychiatry, King's College London, UK

Correspondence: Gareth S. Owen, Department of Psychological Medicine, Institute of Psychiatry, Western Education Centre, Cutcombe Road, London SE5 9RJ. Email: g.owen@iop.kcl.ac.uk

First received 1 Oct 2008, final revision 28 Nov 2008 accepted 21 Jan 2009

\section{Funding}

The study was funded by the Wellcome Trust. M.H. and A.S.D. are supported by the Biomedical Research Centre for Mental Health at the Institute of Psychiatry, King's College London, and The South London and Maudsley NHS Foundation Trust.

\section{Acknowledgements}

We thank the patients and the ward staff

\section{Appendix}

\section{Criteria for detention in hospital under the Mental Health Act 1983 (as amended by the Mental Health Act 2007)}

A person can be detained for assessment under section 2 only if both the following criteria apply:

(a) the person is suffering from a mental disorder of a nature or degree which warrants their detention in hospital for assessment (or for assessment followed by treatment) for at least a limited period; and

(b) the person ought to be so detained in the interests of their own health or safety or with a view to the protection of others.

A person can be detained for treatment under section 3 only if all the following criteria apply:

(a) the person is suffering from a mental disorder of a nature or degree which makes it appropriate for them to receive medical treatment in hospital;

(b) it is necessary for the health or safety of the person or for the protection of other persons that they should receive such treatment and it cannot be provided unless the patient is detained under this section; and

(c) appropriate medical treatment is available.

Department of Health. Code of Practice Mental Health Act 1983: 24. TSO (The Stationery Office), 2008.

\section{References}

$1 \quad R$ V Bournewood Community and Mental Health Trust ex parte L [1998] 3 All ER $289 \mathrm{HL}$.

$2 H L V$ The UK [2005] EHRR 32

3 Department of Health. Code of Practice Mental Health Act 1983: 27-31. TSO (The Stationery Office), 2008.

4 Department of Health. Deprivation of Liberty Safeguards. TSO (The Stationery Office), 2008.

5 Szmukler G, Holloway F. Mental health legislation is now a harmful anachronism. Psychiatr Bull 1998; 22: 662-5.

6 Thornicroft G. Shunned: Discrimation Against People with Mental Disorder Oxford University Press, 2006.

7 Richardson G. Balancing autonomy and risk: a failure of nerve in England and Wales? Int J Law Psychiatry 2007; 30: 71-80. 
8 World Health Organization. The ICD-10 Classification of Mental and Behavioural Disorders: Clinical Descriptions and Diagnostic Guidelines. WHO, 1992.

9 Grisso T, Appelbaum PS, Hill-Fotouhi C. The MacCAT-T: a clinical tool to assess patients' capacities to make treatment decisions. Psychiatr Serv 1997; 48: 1415-9.

10 The Law Commission. Mental Incapacity: 231. HMSO, 1995.

11 Grisso T, Appelbaum PS. Assessing Competence to Consent to Treatment. Oxford University Press, 1998.

12 Okai D, Owen G, McGuire H, Singh S, Churchill R, Hotopf M. Mental capacity in psychiatric patients. Systematic review. Br J Psychiatry 2007; 191: 291-7.

13 Cairns R, Maddock C, Buchanan A, David AS, Hayward P, Richardson G, et al. Reliability of mental capacity assessments in psychiatric in-patients. Br J Psychiatry 2005; 187: 372-8.

14 Sanz M, Constable G, Lopez-Ibor I, Kemp R, David AS. A comparative study of insight scales and their relationship to psychopathological and clinical variables. Psychol Med 1998; 28: 437-46.
15 Ventura J, Green MF, Shaner A, Liberman RP. Training and quality assurance with the Brief Psychiatric Rating Scale: 'The drift buster'. Int J Methods Psychiatr Res 1993; 3: 221-44.

16 Kay SR, Wolkenfeld F, Murrill LM. Profiles of aggression among psychiatric patients. II. Covariates and predictors. J Nerv Ment Dis 1988; 176: 547-57.

17 Gardner W, Hoge SK, Bennett N, Roth LH, Lidz CW, Monahan J, et al. Two scales for measuring patients' perceptions for coercion during mental hospital admission. Behav Sci Law 1993; 11: 307-21.

18 Owen G, Richardson G, David A, Szmuker G, Hayward P, Hotopf M. Mental capacity to make decisions on treatment in people admitted to psychiatric hospitals: a cross sectional study. BMJ 2008; 337: 448.

19 David AS. Insight and psychosis. Br J Psychiatry 1990; 156: 798-808. 20 R (Wilkinson) v Broadmoor Special Hospital Authority [2001] EWCA Civ 1545. $21 R$ (on the application of B) $v$ Dr SS and others [2006] EWCA Civ 28.

\section{Psychiatrists in 19th-century fiction}

\section{Dracula (1897), Bram Stoker}

\section{Fiona Subotsky}

Bram Stoker (1847-1912) came from an Irish medical family whose influence is not hard to detect in his most famous work, Dracula, which sadly did not bring him the fame and fortune which his older brother William Thornley achieved. The latter was not only President of the Irish College of Surgeons and knighted, but held appointments at the two major Dublin asylums - the Richmond Hospital and St Patrick's. He was even a member of the Medico-Psychological Society for a while, and thus was well-placed to advise on the activities and thought-processes of the doctors in Dracula.

Dr John Seward, MD, is the well-to-do owner of one of the largest private asylums in London, where he resides, unaware until well into the story that the vampire count has his sanctuary next door in the ancient mansion of Carfax, with its dusty chapel full of 'earth-boxes'. Seward refused by the beautiful Lucy, takes an interest in the special patient Renfield, feeling proud at his novel diagnosis of 'zoophagous maniac'. He underestimates his patient's dangerousness, however, and is severely assaulted, after which Renfield is put into a strait-waistcoat and 'chained to the wall in a padded room'. Seward's medical practice otherwise seems to comprise making his rounds and giving narcotics, such as morphine and chloral, to himself, his friends and his patients. He dictates his notes into a phonograph, which supplies much contemporaneous material for the narrative. When Lucy falls mysteriously ill, with a strange lassitude and pallor, Seward calls on his old teacher from Amsterdam, Professor Van Helsing, who has not only medical but legal and philosophical qualifications. The approach of the two doctors of the mind is contrasted: Seward is a materialist and an admirer of Ferrier. Van Helsing, who is interested in the work of Charcot and Lombroso, extends their ideas into the realm of the supernatural suggesting that hypnosis is but a short way from telepathy and that Dracula is a kind of un-dead 'throwback' with an infantile and criminal mind. Despite their differences they become an effective team, their medical skills being called on first to revive Lucy with blood transfusions, and then to bring Renfield round from a head injury with a craniotomy. Again, Van Helsing takes things further, using the contents of his capacious medical bag for variously breaking and entering, and of course for 'staking' Lucy-as-Vampire and cutting off her head. However, as they chase Dracula across Europe, and into Transylvania, so the scientific and technical approach is less and less evident, and the power of ancient lore comes into its own.

Vampirism does seem in this novel to be some sort of disease. Medical commentators and others have interpreted the story as referring to specific infections, consciously or unconsciously: the appearance of the thousands of rats has suggested the plague, 'un-deadness' and Stoker's mother's tales of early experiences have suggested cholera, mentions of blood, pallor and sudden changes have suggested tuberculosis, the biting has suggested rabies, and last but not least the sexualised and bloody transmission and the possible cause of Stoker's death have suggested syphilis. Dr Van Helsing, in an up-to-date manner, recommends 'sterilisation' of the earth-boxes to prevent the spread. 